Check for updates

Cite this: RSC Adv., 2019, 9, 28695

Received 18th July 2019

Accepted 6th September 2019

DOI: $10.1039 / c 9 r a 05542 h$

rsc.li/rsc-advances

\section{Barrier effect of coal bottom ash-based geopolymers on soil contaminated by heavy metals $\uparrow$}

\author{
Yiqie Dong, ${ }^{a}$ Min Zhou, ${ }^{\text {ab }}$ Yuwei Xiang, ${ }^{a}$ Sha Wan, ${ }^{a} \mathrm{He} \mathrm{Li}{ }^{a}$ and Haobo Hou (DD *ab
}

Coal bottom ash (CBA) was modified on the basis of the engineering problems of low resource utilization of CBA and difficulty in treating HMS through alkali activation to synthesize geopolymers and solidify heavy metal-contaminated soil (HMS). The optimal values of geopolymers were selected through response surface methodology. Their mineral compositions, microstructure, and binding energy were determined through X-ray diffraction, X-ray photoelectron spectroscopy, and scanning electron microscopy tests, respectively. The stress-strain curve, the leaching concentration and fraction of heavy metals, and the solidifying mechanism for remolded soil were determined through unconfined compressive strength, leaching toxicity, sequential chemical extraction, and infrared (IR) spectroscopy tests, respectively. Based on these experiments, the following conclusions were presented. The optimum ratios of CBA-based geopolymers were $n(\mathrm{Si}): n(\mathrm{Al})=2.666, n(\mathrm{Na}): n(\mathrm{Al})=0.687$, and $n$ (water) $: n$ (binder $)=2.422$. The X-ray curves of the geopolymers were obvious hump-like protuberances at diffraction angles of $20-35^{\circ}$ and had a dense amorphous structure on the surface. The maximum binding energies of Si $2 p$ and Al $2 p$ decreased to 101.03 and $72.89 \mathrm{eV}$, respectively. A 3D network polymerized because of strong geopolymerization. The maximum axial stress of the remolded soil was $104.91 \%$ higher than that of the undisturbed soil, and the leaching concentration decreased by more than $45.88 \%$. The leaching toxicity met the requirements of standard GB 5085.3-2007. The proportion of the acid-extractable fraction of heavy metals in the remolded soil decreased, whereas the proportion of residual fraction increased. The stretching vibration of $\mathrm{Si}-\mathrm{O}-\mathrm{Si}(\mathrm{Al})$ and the bending vibration of $\mathrm{Si}-\mathrm{O}-\mathrm{Si}$ appeared in the IR spectrum. The soil particles were completely encapsulated by a hardened geopolymer structure, thereby forming a multilayer space-skeleton barrier structure that could greatly improve the mechanical properties.

\section{Introduction}

Coal is the main raw material for electric power production. In 2017, 4.49 billion tons of standard coal was consumed in China. Coal combustion can provide power and generate a considerable amount of coal bottom ash (CBA). Many spaces are occupied by stacks of CBA, and rain erosion will cause significantly polluted soil and surface water. ${ }^{1-3}$ Soil pollution is an important problem worldwide, and $82.8 \%$ of soil pollution is caused by heavy metals. The natural environment and human health are seriously threatened by heavy metal-contaminated soil (HMS), and polluted soil needs to be remediated urgently. ${ }^{4,5}$

Poykio et al. ${ }^{6}$ found that CBA has an environmental risk, especially cadmium in CBA, and the value of the leaching

${ }^{a}$ School of Resource and Environmental Sciences, Wuhan University, Wuhan, China. E-mail:houhb@whu.edu.cn

${ }^{b}$ Hubei Environmental Remediation Material Engineering Technology Research Center, Wuhan, China

$\dagger$ Electronic supplementary information (ESI) available. See DOI: 10.1039/c9ra05542h concentration of heavy metals of CBA is higher than the risk assessment criteria. Therefore, scholars investigated harmlessbased treatment and resource-based utilization of CBA. Kinnarinen ${ }^{7}$ developed a new treatment sequence enabling the straightforward and effective recovery of hazardous trace elements from CBA and obtained a positive effect. Samiullah ${ }^{8}$ studied the adsorption behavior of CBA to purify nickel heavy metal ion-bearing water and verified that CBA has a good effect on water purification. Scientists also found that CBA can be used as a modifier for building materials. Park et al. and Lin et al. ${ }^{\mathbf{9}, 10}$ investigated the feasibility of CBA as concrete aggregate and cement mixture. Singh ${ }^{11}$ utilized CBA in recycled concrete aggregate-based self-compacting concrete blended with metakaolin. Poinot ${ }^{\mathbf{1 2}}$ synthesized alkali-activated bricks by using CBA, and the compressive strength of bricks reached 11-15 MPa after 28 days of maintenance. Previous studies indicated that CBA has a high utility value.

Soil leaching, phytoremediation, and solidification and stabilization $(\mathrm{S} / \mathrm{S})$ are common remediation technologies for HMS. In soil-leaching technology, Isoyama ${ }^{\mathbf{1 3}}$ used inorganic compounds, such as acid, alkali, and salt, as eluents to 
remediate HMS. They showed that the binding state of functional groups on soil surface and heavy metals can be broken through acidolysis, complexation, or ion exchange reaction, and pollutants are dissolved from soil. Luo and Tandy ${ }^{\mathbf{1 4 , 1 5}}$ found that EDTA and chelating agents are effective in leaching heavy metals. However, soil-leaching technology has some defects, such as the high costs and secondary treatment of eluents. In phytoremediation technology, $\mathrm{Gu}$ and $\mathrm{Luo}^{\mathbf{1 6 , 1 7}}$ used various plants to remediate mine soils and industrial sites polluted by heavy metals and achieved obvious effects. Nevertheless, phytoremediation is generally a long process. $\mathrm{S} / \mathrm{S}$ can reduce the migration of heavy metals by mixing cementitious materials and soil. ${ }^{18,19}$ Yin $^{20,21}$ synthesized a new cementitious material containing industrial or agricultural wastes and cement to solidify HMS. The leaching concentration of heavy metals of HMS is greatly reduced, and the unconfined compressive strength is increased obviously. S/S has the advantages of low cost, short treatment time, wide application range, and no pretreatment requirement.

Geopolymers are aluminosilicate inorganic polymers with an amorphous or partially crystallized structure and a 3D spatial network structure; ${ }^{22}$ they are considered new building materials and environmental functional materials due to their excellent strength and ability of solidified contaminants. Traditional geopolymers are made of calcined kaolin as the main material and silica sand as an auxiliary material; their compressive strength reaches $82.5 \mathrm{MPa}^{23}$ Scientists investigated the adsorption of pollutants by geopolymers. Wang ${ }^{24}$ compound a fly ash-based geopolymer under various conditions to adsorb $\mathrm{Cu}^{2+}$ in water and confirmed that the adsorption properties of the fly ash-based geopolymer are better than those of natural zeolite and fly ash. Geopolymers also have good performance in acid, alkali, and corrosive radiation resistance. ${ }^{25,26}$

High amounts of $\mathrm{SiO}_{2}$ and $\mathrm{Al}_{2} \mathrm{O}_{3}$ are found in $\mathrm{CBA},{ }^{27}$ and geopolymers can be synthesized by using CBA. However, few studies have focused on solidifying HMS by geopolymers. In the present study, CBA-based geopolymers were synthesized through alkali excitation with reference to traditional synthesis methods for geopolymers. The effects of the strength of the geopolymers were investigated with Design Expert 9.0.5. X-ray diffraction (XRD), X-ray photoelectron spectroscopy (XPS), and scanning electron microscopy (SEM) were performed to analyze the reaction of the CBA-based geopolymers, explore the mechanism of polymerization reaction, and select the best ratio of the geopolymers. HMS with high contents of total cadmium (Cd), total chromium ( $\mathrm{Cr}$ ), and total lead $(\mathrm{Pb})$ was solidified by the CBA-based geopolymers. Unconfined compressive strength and leaching toxicity tests were conducted to evaluate macromechanical and leaching properties, and sequential chemical extraction test (BCR), infrared (IR) spectroscopy test, and SEM were performed to examine the solidifying mechanism.

\section{Materials and methods}

\subsection{Testing materials}

CBA was collected from a power plant in Shandong, China. The chemical compositions of CBA are shown in Table $\mathrm{S} 1, \dagger$ and the particle size distribution is depicted in Fig. S1. $\dagger$ The median diameter of the CBA was 35.687 micron. Before the test was performed, CBA was crushed into powder by using a planetary ball mill, dried at $105{ }^{\circ} \mathrm{C}$ until a constant weight was obtained, and stored sealed.

HMS was collected from the center of an abandoned chemical site (CLA) and $1 \mathrm{~km}$ around the site center (CLB) in Wuhan, China. The selected soil had $1 \mathrm{~m}$ depth and belonged to shallow soil, and the natural moisture was $13 \%$. In sampling, the soil was collected longitudinally and sealed in a bag to reduce disturbance caused by external conditions. The content of heavy metals in the soil is shown in Table $\mathrm{S} 2, \uparrow$ and total $\mathrm{Cd}$, total $\mathrm{Cr}$, and total $\mathrm{Pb}$ in CLA and CLB exceeded the upper limits of standards ("Environmental quality standard for soils" (GB 15618-1995) and "Soil environmental quality risk control standard for soil contamination of development land" (GB366002018)).

\subsection{Experimental design}

A Box-Behnken experimental design ${ }^{28}$ and response surface methodology $(\mathrm{RSM})^{29}$ were used to evaluate the combined effects at three levels. The relationship between factors and response values were expressed via the multivariate quadratic regression equation, and the optimum technological parameters were determined by analyzing the regression equation. ${ }^{30}$ In the experiment, the molar ratios of silicon to aluminum $(n(\mathrm{Si}): n(\mathrm{Al}))$, sodium to aluminum $(n(\mathrm{Na}): n(\mathrm{Al}))$, and water to binder ( $n$ (water) : $n$ (binder)) were chosen as impact factors, and the geopolymer strength was selected as the response value. The experimental range and levels of independent variables are shown in Table S3. $\uparrow$ Design Expert 9.0.5 was used to determine the following equation:

$$
Y=\beta_{0}+\sum_{i=1}^{m} \beta_{i} x_{i}+\sum_{i=1}^{m} \beta_{i i} x_{i}^{2}+\sum_{i=1}^{m} \sum_{j=1}^{m} \beta_{i j} x_{i} x_{j},
$$

where $\beta_{0}$ is the offset term, $\beta_{i}$ is of the first order (linear), $\beta_{i i}$ is of the second order, $\beta_{i j}$ is the interaction effect between $x_{i}$ and $x_{j}$, and $x_{1}, x_{2}, \ldots, x_{k}$ are the coded independent variables. ${ }^{\mathbf{3 0}}$

\subsection{Material synthesis}

The raw materials of the CBA-based geopolymers were CBA, sodium silicate $\left(\mathrm{Na}_{2} \mathrm{O}_{3} \cdot 3 \mathrm{SiO}_{2}\right)$, aluminum correction material $\left(\mathrm{NaAlO}_{2}\right)$, sodium hydroxide $(\mathrm{NaOH})$, and deionized water. The CBA-based geopolymers were prepared as follows: CBA powder was mixed with an alkali solution and stirred with a magnetic bar for $15 \mathrm{~min}$ to ensure sufficient reactions between the particles and the solution. The resulting slurry was cast in cubic molds $(20 \mathrm{~mm} \times 20 \mathrm{~mm} \times 20 \mathrm{~mm}),{ }^{31}$ cured in an oven at $80{ }^{\circ} \mathrm{C}$ for $24 \mathrm{~h}$, and cured again at ambient conditions for the next 27 days before the test.

\subsection{Analysis of synthesis mechanism}

The geopolymer samples were placed in anhydrous ethanol at the age of 28 days $^{32}$ and removed after $24 \mathrm{~h}$ to terminate the hydration reaction. An unconfined compressive strength test 
was performed on the cured geopolymer samples by using a universal compression test machine with a capacity of $60 \mathrm{kN}$ at the age of 28 days according to the Chinese Standard JGJ/T 702009. The samples of each ratio were tested three times, and the average was taken as the compressive strength after the abnormal value was removed.

Chemical and microstructural changes in the raw powdered samples and geopolymers were detected through XRD, XPS, and SEM. Before the test was performed, the geopolymers were dried at $40{ }^{\circ} \mathrm{C}$ until a constant weight was achieved. For SEM analysis, the geopolymers were broken into blocks artificially, and the magnification in the test was 5000 times. For XRD and XPS analyses, the geopolymers were broken into powder and passed through a $45 \mu \mathrm{m}$ sieve. XRD was performed with an X'Pert Pro X-ray diffractometer (Panalytical, Netherlands) with a scan step size of $0.026^{\circ}$ per step for $2 \mathrm{~h}$ from $10^{\circ}$ to $80^{\circ}$, and phase was identified using Jade 6 . The samples were subjected to XPS measurements with an ESCALAB 250Xi spectrometer and $\mathrm{Al} \mathrm{K}$ radiation. The testing conditions were a source power of $400 \mathrm{~W}$ and a pass energy of $37.25 \mathrm{eV}$.

\subsection{Effect and mechanism of remolded soils}

CLA and CLB were undisturbed soils without geopolymer solidification. The optimum ratios of various factors in the geopolymers were selected. The contents of geopolymers and HMS in remolded soils are shown in Table S4. $\dagger$ The remolded soils were formed by pressure under the conditions of maximum compactness and optimum moisture content in accordance with the Chinese Standard JTG E40-2007, and steel mold with a size of $\varphi 50 \times 50 \mathrm{~mm}$ was used in the test. The remolded soils were maintained for 28 days under the standard conditions of $20{ }^{\circ} \mathrm{C}$ and $95 \%$ humidity. The unconfined compressive strength test was performed to evaluate the strength of remolded soils, and the speed of load application was $0.5 \mathrm{~mm} \mathrm{~s}^{-1}$.

"Solid waste-extraction procedure for leaching toxicity, sulfuric acid, and nitric acid method" (HJ/T 299-2007) was used to evaluate the leaching characteristics of remolded soils. The leaching solution was a mixture solution with $66.7 \%$ sulfuric acid and $33.3 \%$ nitric acid, and the liquid-solid ratio was $10: 1$. The supernatant was taken after $18 \mathrm{~h}$ of rotary oscillation, and the content of heavy metals was measured through ICP-AES. The relative leaching rate (RLR) of heavy metals was calculated using the following equation:

$$
\mathrm{RLR}=\frac{C V}{C_{0} m_{0}} \times 100 \%,
$$

where $C$ is the leaching concentration of heavy metals $\left(\mathrm{mg} \mathrm{L}^{-1}\right)$, $V$ is the volume of buffer solution (L), $C_{0}$ is the mass concentration of heavy metals $\left(\mathrm{mg} \mathrm{kg}^{-1}\right)$, and $m_{0}$ is the quality of soil $(\mathrm{kg})$.

BCR was utilized to detect the heavy metal fraction in remolded soils, Table $55 \dagger$ describes the procedure of chemical fraction distribution. Four fractions of the metals, including acid extractable, reducible, oxidizable, residual were categorized following the methods mentioned below. The liquid-solid mixture produced in each step was centrifuged for 20 minutes. The residue was washed twice with $5 \mathrm{ml}$ of deionized water and centrifuged for the next step, the washing liquid was mixed with the supernatant in each step, and was analyzed for the concentrations of trace elements via ICP-AES. Parallel tests were conducted twice, and the average value was taken as the test result. IR spectroscopy was conducted to characterize the composition of functional groups in remolded soils.

\section{Results and discussion}

\subsection{Synthesis of geopolymers}

3.1.1 RSM analysis. The following second-order polynomial equation was established by applying multiple regression analysis on the design matrix and responses to help find the optimal conditions:

$$
\begin{aligned}
Y= & -196.48056 X_{1}{ }^{2}-332.325 X_{2}^{2}-27.56719 X_{3}^{2}+47.41667 X_{1} X_{2} \\
& -16.875 X_{1} X_{3}-106.75 X_{2} X_{3}+1055.99083 X_{1}+588.9425 X_{2} \\
& +251.885 X_{3}-1884.403
\end{aligned}
$$

where $Y$ is the predicted strength; and $X_{1}, X_{2}$, and $X_{3}$ are the coded terms of three independent test variables, namely, $n(\mathrm{Si}): n(\mathrm{Al}), n(\mathrm{Na}): n(\mathrm{Al})$, and $n($ water $): n$ (binder), respectively.

Table 1 presents the ANOVA of the response surface model. The $F$-value denotes the significance in the model equation. ${ }^{33}$ The model $F$-value of 168.13 showed that the quadratic model was highly significant. Only a $0.01 \%$ chance that a large $F$-value could occur due to noise was determined.

The regression and corresponding value of "Prob. $>F$ " less than 0.0500 indicated that the model terms were significant. In this case, $X_{1}, X_{1} X_{2}, X_{1} X_{3}, X_{2} X_{3}, X_{1}^{2}, X_{2}{ }^{2}$, and $X_{3}{ }^{2}$ were significant model terms. ${ }^{34}$ The "Pred. $R^{2}$ " of 0.9385 was in reasonable

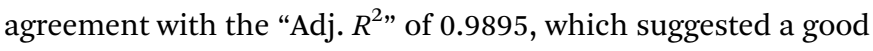
consistency between experimental and predicted values.

The 3D response surfaces were generated with Design Expert (Fig. 1). When interactions of two variables were discussed, the third factor was kept at the zero level. 3D response surfaces and their corresponding contour plots can facilitate the straightforward examination of the effects of experimental variables on responses. ${ }^{35}$

S-1 reveals that $n(\mathrm{Si}): n(\mathrm{Al})$ and $n(\mathrm{Na}): n(\mathrm{Al})$ had a strong synergistic effect on strength reduction. The surface shown in the figure was obviously spherical. When $n(\mathrm{Si}): n(\mathrm{Al})$ and $n(\mathrm{Na}): n(\mathrm{Al})$ increased, the strength first increased and then decreased. The maximum strength appeared at the vertex of the surface. S-2 shows that the influence of $n(\mathrm{Si}): n(\mathrm{Al})$ on strength was greater than that of $n$ (water) $: n$ (binder). At $n$ (water)$: n$ (binder) of 2-2.8, a minimal increase in $n(\mathrm{Si}): n(\mathrm{Al})$ had an obvious effect on strength. At $n(\mathrm{Si}): n(\mathrm{Al})$ of $2.4-3.0$, the change in strength was relatively weak. S-3 depicts the interactive influence between $n(\mathrm{Na}): n(\mathrm{Al})$ and $n$ (water) $: n$ (binder). At low $n(\mathrm{Na}): n(\mathrm{Al}), \quad$ strength increased as $n$ (water) $: n$ (binder) increased. At $n(\mathrm{Na}): n(\mathrm{Al})=0.7$, an opposite effect was observed. In Fig. 1, the peak appeared in the middle of the surface, showing that the range of the factors selected was reasonable. 
Table 1 ANOVA of the response surface model

\begin{tabular}{|c|c|c|c|c|c|}
\hline Source & Sum of squares & $d_{\mathrm{f}}$ & Mean square & $F$-Value & Prob $>F$ \\
\hline Model & 1733.66 & 9 & 192.63 & 168.13 & $<0.0001$ \\
\hline$X_{1} n(\mathrm{Si}): n(\mathrm{Al})$ & 109.15 & 1 & 109.15 & 95.27 & $<0.0001$ \\
\hline$X_{3} n($ water $): n$ (binder $)$ & 0.67 & 1 & 0.67 & 0.59 & 0.4685 \\
\hline$X_{1} X_{2}$ & 8.09 & 1 & 8.09 & 7.06 & 0.0326 \\
\hline$X_{1} X_{3}$ & 16.40 & 1 & 16.40 & 14.32 & 0.0069 \\
\hline$X_{2}^{2}$ & 46.50 & 1 & 46.50 & 40.59 & 0.0004 \\
\hline$X_{3}^{2}$ & 81.91 & 1 & 81.91 & 71.50 & $<0.0001$ \\
\hline Residual & 8.02 & 7 & 1.15 & & \\
\hline Lack of fit & 6.55 & 3 & 2.18 & 5.96 & 0.0588 \\
\hline Pure error & 1.47 & 4 & 0.37 & & \\
\hline
\end{tabular}

On the basis of the calculation steps defined for the optimization algorithm, we found the following optimal values of the test variables: $n(\mathrm{Si}): n(\mathrm{Al})=2.666, n(\mathrm{Na}): n(\mathrm{Al})=0.687$, and $n$ (water) $: n$ (binder) $=2.422$, with strength $=30.74 \mathrm{MPa}$.

Several additional batch tests were performed in the experimental area of the Box-Behnken design to verify the validity of the proposed model. Three groups were randomly selected to carry out the experiment, and the results were compared with the predicted values of the model. The test results are listed in Table 2. The geopolymer of S1 is shown in Fig. S2. $\dagger$ The tests were in close agreement with the model prediction and showed that the model was effective.

3.1.2 XRD analysis. A change in mineral phase is a sign of alkali excitation effect. Samples used in X-ray diffraction, X-ray photoelectron spectroscopy, and scanning electron microscopy tests are the same as Table 2 . Fig. $\mathrm{S} 3 \dagger$ shows the XRD diagram of CBA and geopolymers. According to the JCPDS card, the diffraction peaks of quartz, mullite, pyrophyllite, and hematite were conspicuous in CBA and disappeared in geopolymers. The diffraction peaks of elemental iron were evident in S3 and S4, and the curves of S1 and S2 had obvious hump-like protuberances at diffraction angles of $20-35^{\circ}$, which were the characteristics of geopolymerization.

Mineral facies, such as quartz, mullite, and pyrophyllite, in CBA are binary compounds in the $\mathrm{Al}_{2} \mathrm{O}_{3}-\mathrm{SiO}_{2}$ system, and silica-aluminate easily decomposes in an alkali solution, thereby increasing the active monomers of $\mathrm{Al}$ and $\mathrm{Si}$ in the reaction system and promoting polymerization. ${ }^{36,37} \mathrm{CBA}$ is composed of a large amount of iron compounds, which are dissolved by a strong alkali solution and gradually transformed into elemental iron in geopolymers. ${ }^{38}$ The curves of S1 and S2 were smoother than those of S3 and S4, with fewer diffraction peaks. The curves indicated that the polymerization of S1 and S2 was more intense, which confirmed the trend of strength (Table 2).

3.1.3 SEM analysis. Microstructure can intuitively show the mechanical characteristics of geopolymers. The micromorphologies of S1, S4 (28 days of maintenance), and CBA are depicted in Fig. S4. $\uparrow$ The CBA showed a layered debris structure with uneven size and shape, and particle distribution was disordered. S1 showed a dense and uniform amorphous structure with strong integrity. $\mathrm{S} 2$ exhibited an amorphous structure, which was a superimposed layered aggregate, and multiple pores and cracks appeared on the surface. When CBA was activated by mechanical force, its irregular shape was destroyed, and the uniformity of particles was improved. Homogeneous particles contribute to the full mixing of solid and liquid phases to form dense amorphous geopolymers. ${ }^{39}$ The structure and morphological characteristics were different due to the degree of polymerization; the completed geopolymerization of S1 showed a neat morphology, whereas the limited geopolymerization of S4 exhibited a rough morphology.

Fig. S5 $\uparrow$ presents the energy spectrum curves of the characteristic points in S1 and S4. S1 was mainly composed of $\mathrm{Na}, \mathrm{Al}$, $\mathrm{Si}$, and $\mathrm{O}$. The amorphous substance of aluminosilicate is formed through geopolymerization. ${ }^{40}$ The element composition of S4 was similar to that of S1, but Fe and K existed in the gaps. The CBA composition was complex. The geopolymer did not completely encapsulate impurities because of the inadequate geopolymerization, and this observation was consistent with the results of XRD analysis.

3.1.4 XPS analysis. After alkali excitation occurred, the crystalline substances in the powder underwent a physicochemical reaction to form new mineral phases. XPS analysis was conducted to compare the excitation effects of the samples. Fig. S6 $\uparrow$ shows the binding energies of Si $2 \mathrm{p}$ and Al 2p of CBA and samples S1 and S4. The maximum binding energy of Si $2 \mathrm{p}$ of CBA was $102.51 \mathrm{eV}$. After alkali excitation was completed, the maximum binding energy of Si 2p showed a chemical shift, and the binding energies of S1 and S4 decreased to 101.03 and $100.90 \mathrm{eV}$, respectively. This phenomenon indicated the chemical transformation of Si from a crystal to an aggregate or amorphous state. ${ }^{41}$ The binding energy of Al $2 \mathrm{p}$ was similar to that of Si 2p. The maximum binding energy decreased from $74.16 \mathrm{eV}$ to $72.89-73.32 \mathrm{eV}$.

The decrease in maximum binding energies of $\mathrm{Si} 2 \mathrm{p}$ and $\mathrm{Al}$ $2 \mathrm{p}$ caused coordination forms of $\mathrm{Si}$ and $\mathrm{Al}$. Part of the Si in CBA existed in the form of $\mathrm{SiO}_{1.02}-\mathrm{SiO}_{1.49}$; with the progress of 


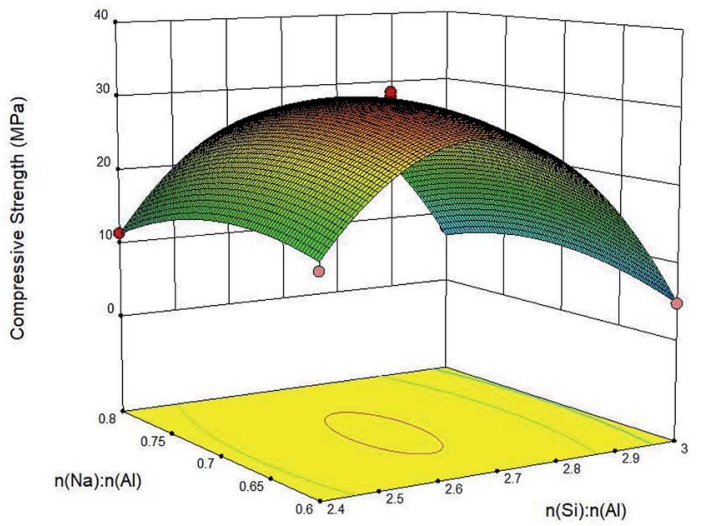

(S-1)

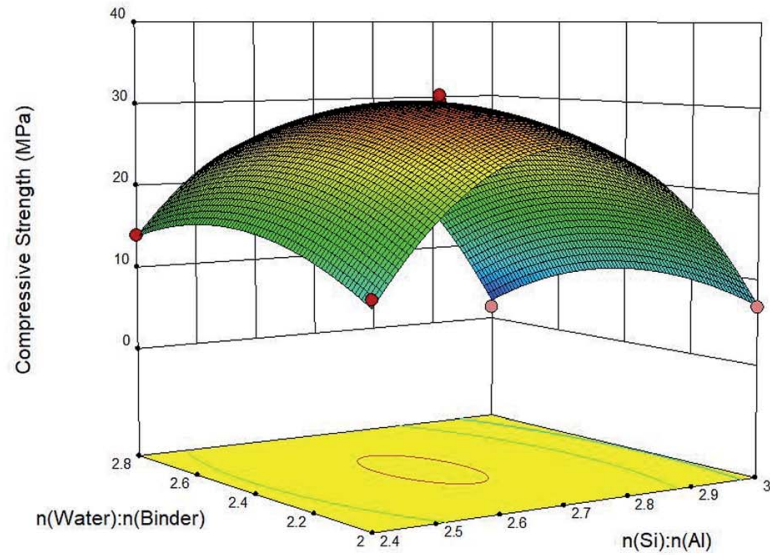

$(\mathrm{S}-2)$

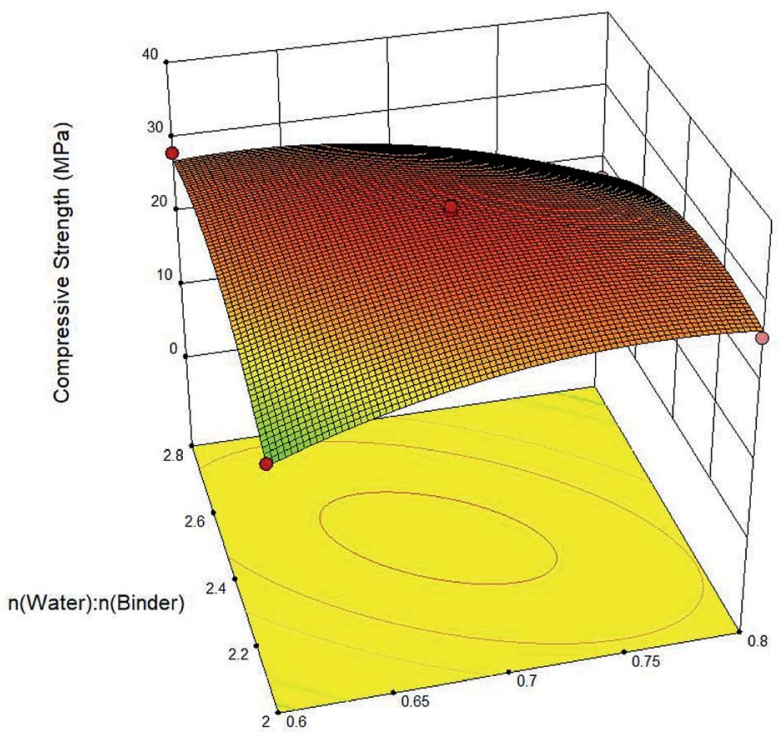

$n(\mathrm{Na}): n(\mathrm{Al})$

Fig. 1 Three-dimensional response surface plots: $\mathrm{S}-1 \quad n(\mathrm{Si}): n(\mathrm{Al})$ and $n(\mathrm{Na}): n(\mathrm{All}) ; \mathrm{S}-2 n(\mathrm{Si}): n(\mathrm{Al})$ and $n($ water $): n($ binder); and S-3 $n(\mathrm{Na}): n(\mathrm{Al})$ and $n$ (water) : $n$ (binder)

geopolymerization, the degree of polymerization of $\mathrm{Si}-\mathrm{O}$ changed. Si-O bond broken down and recombined, and the structures of silicon-oxygen tetrahedron and silicon-oxygen octahedron formed (binding energy: 100.4-101.9). Crystallinephase Si transformed into polymer or amorphous state. ${ }^{\mathbf{1 1}}$ Table S1 $\uparrow$ and the maximum binding energy of CBA present that the other $\mathrm{Si}$ and $\mathrm{Al}$ existed in the form of $\mathrm{SiO}_{2}\left(\mathrm{Al}_{2} \mathrm{O}_{3}\right)_{X}(\mathrm{Si} 2 \mathrm{p}$ binding energy: 102.0-102.6, $\mathrm{Al} 2 \mathrm{p}$ binding energy: 74.1-74.6). ${ }^{42}$ The chemical bonds were destroyed to form $\mathrm{AlO}_{x} / \mathrm{Al}, \mathrm{Na}_{12}\left[\mathrm{Al}_{12}-\right.$ $\left.\mathrm{Si}_{12} \mathrm{O}_{48}\right] \cdot 18 \mathrm{H}_{2} \mathrm{O}$, and other structures after alkaline excitation, ${ }^{43}$ and an amorphous system with 3D network polymerization was formed. ${ }^{44}$

3.1.5 Analysis of synthetic mechanism. The minerals in CBA were mostly quartz, pyrophyllite, mullite, and other rock minerals. They were annular and layered silicate materials. Quartz, as a mineral with high content in CBA, was composed of $\left[\mathrm{SiO}_{4}\right]$ tetrahedron and prone to polycondensation to form a $3 \mathrm{D}$ network structure. Pyrophyllite was a double-layer mineral, which had high covalent bond energy because of the structure of Si-O-Al-O-Si. After mechanical activation, the bonding type of chemical bond of pyrophyllite was changed, and the chemical activity was increased; hence, pyrophyllite participated in the geopolymerization.

Each stage of geopolymer formation was not isolation, but it existed in the reaction system as a whole. Fig. 2 demonstrates that after the minerals were attacked by alkali, the crystal structure destroyed from side to inner layer, and alkaline dissociation occurred in the polysiloxane layer, which is the basic unit of geopolymers. ${ }^{45}$ In Fig. 3, with continuous polymerization, the active monomers of $\mathrm{Si}$ and $\mathrm{Al}$ polymerized to form a silica aluminum complex gel. $\mathrm{Si}-\mathrm{O}$ reacted with $\mathrm{Na}^{+}$to form $\mathrm{Si}-\mathrm{ONa}^{+}$end group in the presence of an alkali activator, and the structure transformed to an aluminosilicate polymer network structure and eventually formed a stable 3D network polymerization structure. ${ }^{46}$

\subsection{Effect and mechanism of solidified HMS}

3.2.1 Stress-strain analysis. Fig. $S 7 \dagger$ presents the stressstrain curves of CLA, CLB, and remolded soils. Fig. S8 $\uparrow$ shows the remolded soils of CLA3 and CLB3. The axial stress of undisturbed soils first increased sharply with an increase in axial strain and then decreased slowly. The maximum axial stresses of CLA and CLB were 896 and $1130 \mathrm{kPa}$, respectively, and the corresponding axial strain was $4-6 \%$. When geopolymer was added to the remolded soils, the axial stress increased linearly until it reached the extreme value and then decreased abruptly. The maximum axial stress of the remolded soils was obviously higher than that of the undisturbed soils. The axial stresses of CLA3 and CLB3 were 104.91\% and 91.06\% higher than those of the corresponding undisturbed soils, respectively. The geopolymer promoted the increase in axial stress, and the axial strain of CLA3 and CLB3 was $17-20 \%$, which was higher than that of CLA and CLB.

The results implied that geopolymer improved the mechanical properties of HMS. The undisturbed soils showed a strong resistance to axial deformation during axial stress loading, indicating that the undisturbed soils had structurality and high ultimate strength. The failure form of the undisturbed soils was plastic failure. 
Table 2 Comparison of predicted and experimental values

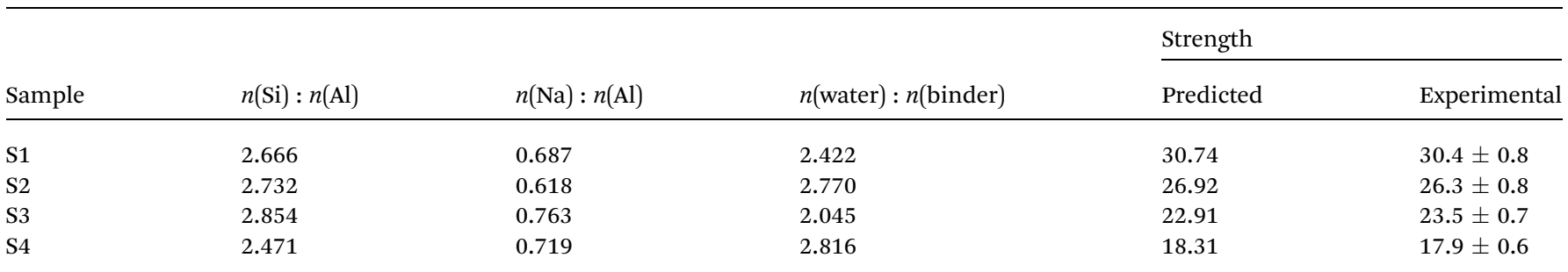

The deformation speed of remolded soils increased linearly as the axial strain increased before the maximum axial stress. When the failure stress was reached, fracture occurred, and the axial stress decreased greatly. The structurality of the remolded soils decreased. The failure form of the remolded soils was brittle fracture. A high content of geopolymer led to an obvious brittle fracture, which was consistent with the destruction of geopolymers. ${ }^{47}$

3.2.2 Leaching toxicity analysis. The mass concentration limits of total $\mathrm{Cd}, \mathrm{Cr}$, and $\mathrm{Pb}$ were 1,15 , and $5 \mathrm{mg} \mathrm{L}^{-1}$, respectively, according to "Identification standards for hazardous wastes-Identification for extraction toxicity" (GB 5085.3-2007). The leaching concentrations of heavy metals in undisturbed and remolded soils are shown in Fig. S9. $\dagger$ The contents of total $\mathrm{Cd}, \mathrm{Cr}$, and $\mathrm{Pb}$ in undisturbed soils were 1.22.7 times of the limit. The contents of heavy metals in remolded soils were lower than the limit and met the abovementioned standards.

The leaching concentration of CLA1 was 58.74-76.25\% lower than that of CLA, whereas the leaching concentration of CLA3 was only $22.26-51.63 \%$ lower than that of CLA1. The leaching concentration of heavy metals could be greatly reduced by adding $10 \%$ geopolymer in HMS. As the geopolymer content increased, the leaching concentration reduction rate decreased. The trends of CLB and CLA were similar. The leaching concentration of CLA was 1.35-2.05 times that of CLB, whereas the leaching concentration of CLA3 was only 1.19-1.53 times that of CLB3. As the geopolymer content increased, the difference in leaching concentration was insignificant.
When geopolymer entered the soil medium, it could fully come in contact with the effective components of soil particles and form a geopolymer layer out of soil particles and heavy metals. Geopolymer could block the leaching of heavy metals due to the stability effect, and the leaching concentration of metals could be greatly reduced. As the geopolymer content increased, the thickness of the geopolymer layer increased. Consequently, the leaching solution experienced difficulty in causing heavy metals to erode.

The RLRs of Cd, Cr, and $\mathrm{Pb}$ are shown in Table 3. The RLRs of $\mathrm{Cr}$ and $\mathrm{Pb}$ were less than that of $\mathrm{Cd}$, indicating that $\mathrm{Cr}$ and $\mathrm{Pb}$ were stable under a strongly acidic environment, and a strongly acidic leaching solution could not increase their leaching rate. $\mathrm{Cr}$ and $\mathrm{Pb}$ were incompletely released due to the limited buffer capacity of the leaching solution, resulting in a low reduction rate of leaching concentration. Disturbing ions (such as $\mathrm{PO}_{4}{ }^{3-}$, $\mathrm{Cl}^{-}$, and $\mathrm{NO}_{3}{ }^{-}$) in HMS can also react with the effective components in geopolymer, and the RLR can be affected.

3.2.3 Chemical species distribution. Fig. S10 $\dagger$ shows the chemical fraction distribution of remolded soils. As the geopolymer content increased, the proportion of acid-extractable fraction decreased. In particular, $28.7 \%$ of CLB1 decreased to $10.4 \%$. The proportion of residual fraction in CLA3 was 5.9$18.0 \%$ higher than that in CLA1, and the proportion of residual fraction in CLB3 was 5.8-30.9\% higher than that in CLB1. The geopolymer slightly affected reducible and oxidizable. The acidextractable fraction proportions of $\mathrm{Cd}, \mathrm{Cr}$, and $\mathrm{Pb}$ of CLA1 were $31.3 \%, 30.2 \%$, and $2.7 \%$, respectively, which were higher than those of the corresponding CLB1. The comparison of the

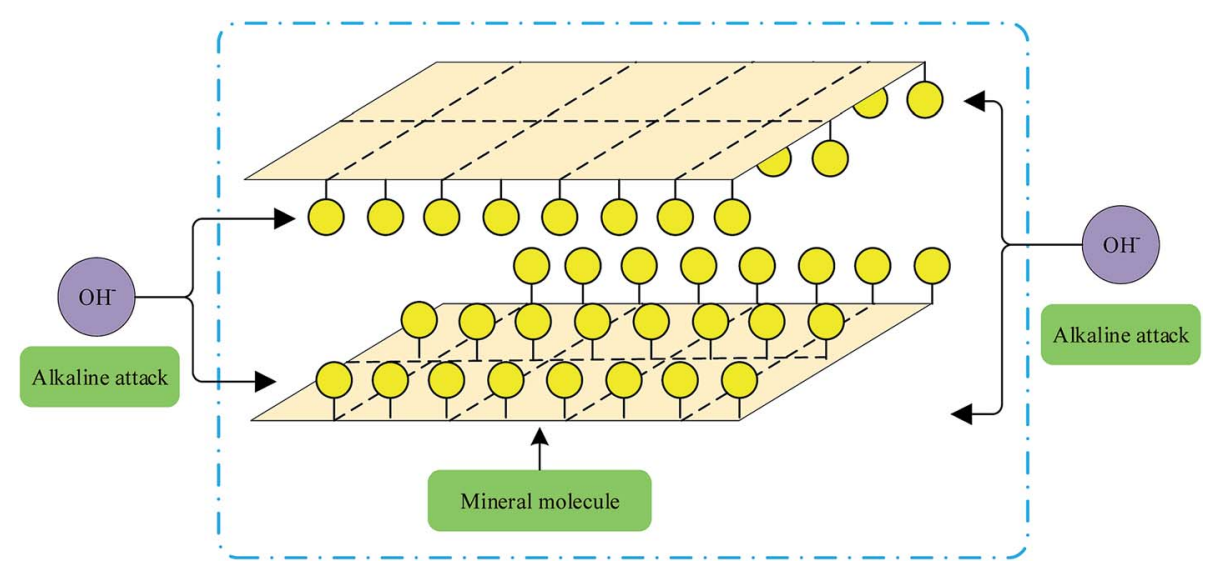

Fig. 2 Mineral molecules attacked by alkalinity. 


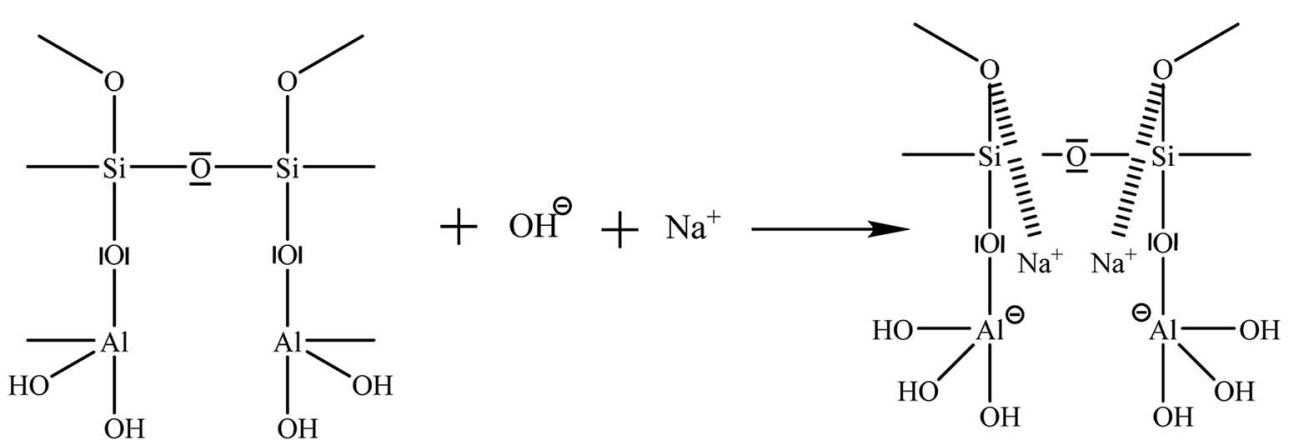

(a)
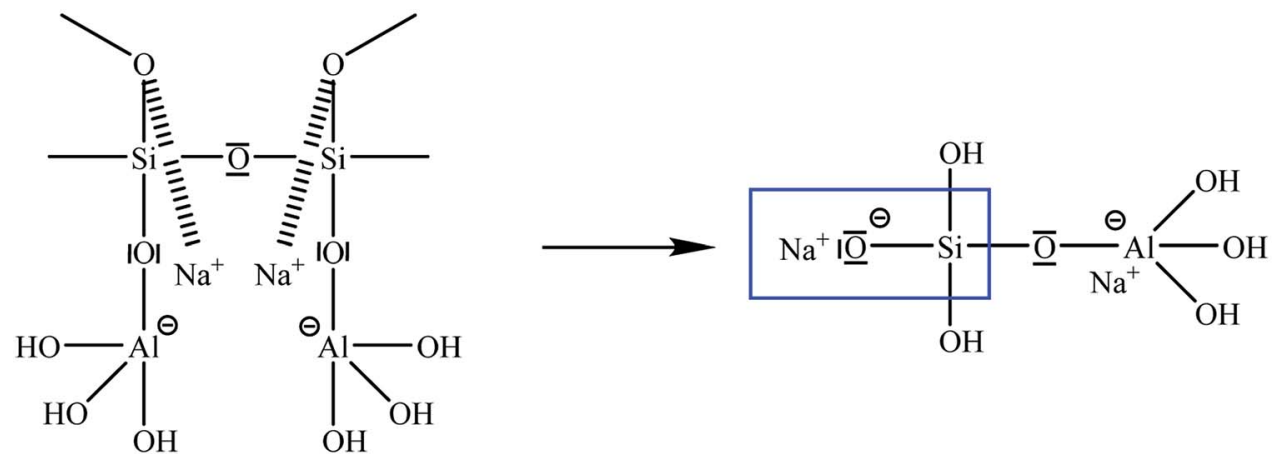

(b)

Fig. 3 Synthesis mechanism.

chemical speciation distribution of different heavy metals showed that the acid-extractable fraction proportion of $\mathrm{Pb}$ was less than $5.0 \%$, which was less than those of $\mathrm{Cd}$ and $\mathrm{Cr}$. The residual fraction of $\mathrm{Pb}$ was more than $30.0 \%$, which was obviously larger than those of $\mathrm{Cd}$ and $\mathrm{Cr}$.

The leaching behavior of heavy metals was determined by the chemical occurrence forms, not by the total amount of heavy metals. The acid-extractable fraction was the heavy metals adsorbed on the mineral surface; with precipitation or coprecipitation, these forms of heavy metals strongly migrate and easily flow into soil or water to cause environmental pollution. ${ }^{48}$ Residual fraction is stable and difficult to leach. ${ }^{49}$ As the geopolymer content increased, heavy metals entered the structure system of the solidified blocks through chemical bonding or physical coating; consequently, the content of residual fraction increased gradually. ${ }^{50}$

3.2.4 Analysis of solidification mechanism. The IR spectrum of remolded soils is shown in Fig. S11. $\dagger$ The stretching vibration of $\mathrm{H}_{2} \mathrm{O}$ occurred merely when the wavenumber was

Table 3 RLR (\%)

\begin{tabular}{lrrllllll}
\hline Sample & CLA & CLA1 & CLA2 & CLA3 & CLB & CLB1 & CLB2 & CLB3 \\
\hline $\mathrm{Cd}$ & 46.51 & 11.04 & 6.71 & 5.34 & 41.90 & 13.10 & 8.96 & 8.29 \\
$\mathrm{Cr}$ & 21.04 & 6.74 & 5.92 & 4.35 & 26.88 & 7.69 & 5.11 & 4.89 \\
$\mathrm{~Pb}$ & 5.38 & 2.22 & 2.02 & 1.73 & 9.52 & 5.15 & 4.39 & 3.77
\end{tabular}

larger than $2500 \mathrm{~cm}^{-1}$, which showed no effect on the reaction system; therefore, the IR spectrum more than $2500 \mathrm{~cm}^{-1}$ was not drawn. The band at $50-470 \mathrm{~cm}^{-1}$ corresponded to the stretching vibration of $\mathrm{Si}-\mathrm{O}-\mathrm{Si}(\mathrm{Al})$; the band at $960-1005 \mathrm{~cm}^{-1}$ mainly reflected the bending vibration of $\mathrm{Si}-\mathrm{O}-\mathrm{Si}$, confirming that the geopolymer structure was formed during the reaction. As the geopolymer content increased, the stretching vibration peak of $\mathrm{Si}-\mathrm{O}-\mathrm{Si}(\mathrm{Al})$ and the bending vibration peak of $\mathrm{Si}-\mathrm{O}-\mathrm{Si}$ gradually sharpened. The structure of aluminosilicate formed in the system was constantly improved, and the structure of remolded soils was more optimized.

The band at $1650 \mathrm{~cm}^{-1}$ reflected the stretching vibration of $\mathrm{H}_{2} \mathrm{O}$. The spectral peak of CLA1 at $1650 \mathrm{~cm}^{-1}$ band was sharper than that of CLA3, indicating that some excess water in CLA1 did not participate in the geopolymer reaction.

The micromorphology of remolded soils is depicted in Fig. S12. $\dagger$ Amorphous substances (spot I, spot II) and penetrating gap (spot III) can be clearly observed in the figure. Regular smooth sheet materials appeared at spots IV and V and should be soil particles covered with geopolymer gel. The particles in CLA3 were closely connected, and no gap existed among particles; only a small amount of irregular debris was free on the surface. ${ }^{40}$

In Fig. 4, heavy metals in soils were mainly concentrated on the surface and in the gaps of particles, and most of them were in a free form. With the infiltration of geopolymer slurry, the soil particles were wrapped by the geopolymer. The particles on the surface were covered with gelatinous slurry, and some heavy 


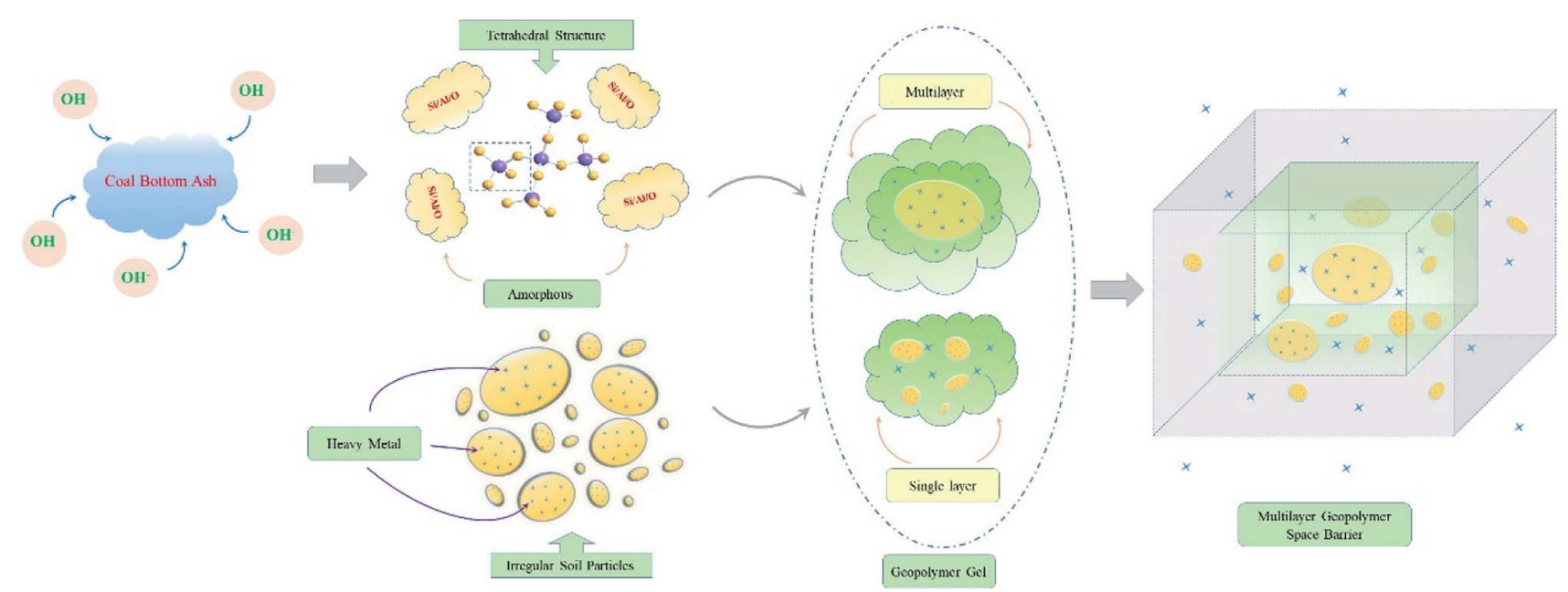

Fig. 4 Solidification mechanism.

metals were absorbed into the gelatinous slurry. ${ }^{51,52}$ As the maintenance time was extended, the gelatinous slurry gradually hardened to form amorphous geopolymers. Influenced by gravity and intermolecular diffusion forces, some of the slurry would migrate slowly in the soil gaps when the geopolymer content was high. The surface of some particles would be covered with a multilayer geopolymer gel due to differences in slurry hardenability in different positions.

After 28 days of maintenance, soil particles were completely encapsulated by the hardened geopolymer, forming a multilayer space-skeleton barrier structure, which could greatly improve the mechanical properties..$^{53}$ During the maintenance, most of the heavy metals were retained in the soil particles and the inner geopolymer structure, and only a small amount of heavy metals were free from the surface geopolymer structure. The leaching toxicity was consequently reduced, and this observation was consistent with the results described in the previous section.

\section{Conclusions}

Based on the results of this study, the following conclusions were obtained:

(1) The theoretical maximum strength of the geopolymers was $30.74 \mathrm{MPa}$ when $n(\mathrm{Si}): n(\mathrm{Al}), n(\mathrm{Na}): n(\mathrm{Al})$, and $n$ (water)$: n$ (binder) were $2.666,0.687$, and 2.422 , respectively. The validation value of the ratio was $30.4 \pm 0.8$. In XRD, no obvious diffraction peak existed in the geopolymers, but obvious humplike protuberances appeared at diffraction angles of $20-35^{\circ}$. The geopolymers had a dense and uniform amorphous structure. The geopolymers were composed of $\mathrm{Na}, \mathrm{Al}, \mathrm{Si}$, and O. CBA geopolymerized under alkaline conditions, the chemical bonds were destroyed to form $\mathrm{AlO}_{x} / \mathrm{Al}, \mathrm{Na}_{12}\left[\mathrm{Al}_{12} \mathrm{Si}_{12} \mathrm{O}_{48}\right] \cdot 18 \mathrm{H}_{2} \mathrm{O}$, and other structures, and an amorphous system with $3 \mathrm{D}$ network polymerization was formed.

(2) The macromechanical property and leaching toxicity of the solidified HMS were significantly improved. The axial stress of the remolded soil with $30 \%$ geopolymer was $91.06-104.91 \%$ higher than that of the undisturbed soil. The leaching concentration of heavy metals in CLA1 was $58.74-76.25 \%$ lower than that in CLA. As the geopolymer content increased, the difference in leaching concentration was insignificant. The leaching toxicity of the remolded soils was lower than the limit set by the standard GB 5085.3-2007.

(3) The proportion of the acid-extractable fraction of heavy metals in the remolded soils decreased, whereas the proportion of the residual fraction increased. The stretching vibration of $\mathrm{Si}-\mathrm{O}-\mathrm{Si}(\mathrm{Al})$ and the bending vibration of $\mathrm{Si}-\mathrm{O}-\mathrm{Si}$ appeared in the IR spectrum. As the geopolymer content increased, the peaks sharpened. The soil particles were completely encapsulated by the hardened geopolymer structure, forming a multilayer space-skeleton barrier structure that could greatly improve the mechanical properties.

\section{Conflicts of interest}

There are no conflicts to declare.

\section{Acknowledgements}

The authors acknowledge the National Key Research and Development Program of China (2017YFC0703307, 2018YFC1801703).

\section{References}

1 S. Oruji, N. A. Brake, L. Nalluri and R. K. Guduru, Constr. Build. Mater., 2017, 153, 317-326.

2 X. Ge, M. Zhou, H. Wang, L. Chen, X. Li and X. Chen, Ceram. Int., 2019, 45, 12528-12534.

3 H. Koca, D. O. Aksoy, R. Ucar and S. Koca, Environ. Technol., 2017, 38, 1673-1678.

4 Y. Huang, Q. Q. Chen, M. H. Deng, J. Japenga, T. Q. Li, X. E. Yang and Z. He, J. Environ. Manage., 2018, 207, 159-168.

5 W. Han, G. Gao, J. Geng, Y. Li and Y. Wang, Chemosphere, 2018, 197, 325-335. 
6 R. Poykio, M. Makela, G. Watkins, H. Nurmesniemi and O. Dahl, Trans. Nonferrous Met. Soc. China, 2016, 26, 256-264.

7 T. Kinnarinen, M. Golmaei, E. Jernstrom and A. Hakkinen, J. Hazard. Mater., 2018, 344, 770-777.

8 M. Samiullah, Z. Aslam, A. G. Rana, A. Abbas and W. Ahmad, Water, Air, Soil Pollut., 2018, 229, 113.

9 S. B. Park, Y. Il Jang, J. Lee and B. J. Lee, J. Hazard. Mater., 2009, 166, 348-355.

10 K. L. Lin, W. C. Chang and D. F. Lin, Constr. Build. Mater., 2008, 22, 324-329.

11 N. Singh, M. Mithulraj and S. Arya, Resour., Conserv. Recycl., 2019, 144, 240-251.

12 T. Poinot, M. E. Laracy, C. Aponte, H. M. Jennings, J. A. Ochsendorf and E. A. Olivetti, Resour., Conserv. Recycl., 2018, 128, 1-10.

13 M. Isoyama and S.-I. Wada, J. Hazard. Mater., 2007, 143, 636642.

14 C. L. Luo, Z. G. Shen and X. D. Li, Chemosphere, 2005, 59, 111.

15 S. Tandy, A. Ammann, R. Schulin and B. Nowack, Environ. Pollut., 2006, 142, 191-199.

16 L.-P. Gu, J.-J. Kong, K. Chen and Y.-Q. Guo, Ecotoxicol. Environ. Saf., 2019, 180, 130-138.

17 J. Luo, L. Cai, S. Qi, J. Wu and X. S. Gu, J. Environ. Manage., 2017, 204, 17-22.

18 D. H. Moon, M. Wazne, I.-H. Yoon and D. G. Grubb, J. Hazard. Mater., 2008, 159, 512-518.

19 D. Dermatas, D. H. Moon, N. Menounou, X. G. Meng and R. Hires, J. Hazard. Mater., 2004, 116, 25-38.

20 C. Y. Yin, H. Bin Mahmud and M. G. Shaaban, J. Hazard. Mater., 2006, 137, 1758-1764.

21 D. Dermatas and X. G. Meng, Eng. Geol., 2003, 70, 377-394.

22 H. Xu and J. S. J. Van Deventer, Int. J. Miner. Process., 2000, 59, 247-266.

23 A. Fernandez-Jimenez, A. Palomo and M. Criado, Cem. Concr. Res., 2005, 35, 1204-1209.

24 S. Wang, L. Li and Z. H. Zhu, J. Hazard. Mater., 2007, 139, 254-259.

25 M. B. M. Salahuddin, M. Norkhairunnisa and F. Mustapha, Ceram. Int., 2015, 41, 4273-4281.

26 F. Pacheco-Torgal, Z. Abdollahnejad, A. F. Camoes, M. Jamshidi and Y. Ding, Constr. Build. Mater., 2012, 30, 400-405.

27 Z. Ma, X. Shan and F. Cheng, ACS Omega, 2019, 4, 6854-6863.

28 M. Raynaud, J. Vaxelaire, P. Heritier and J. C. Baudez, AsiaPac. J. Chem. Eng., 2010, 5, 785-790.

29 M. Pirsaheb, S. Moradi, M. Shahlaei and N. Farhadian, J. Hazard. Mater., 2018, 353, 444-453.
30 K. Yetilmezsoy, S. Demirel and R. J. Vanderbei, J. Hazard. Mater., 2009, 171, 551-562.

31 N. Zhang, H. Li and X. Liu, J. Hazard. Mater., 2016, 314, 172180.

32 Y. C. Chen, X. Zhou, S. Wan, R. Zheng, J. Tong, H. B. Hou and T. Wang, Constr. Build. Mater., 2019, 211, 646-658.

33 H. L. Liu, Y. W. Lan and Y. C. Cheng, Process Biochem., 2004, 39, 1953-1961.

34 L.-P. Wong, M. H. Isa and M. J. K. Bashir, Process Saf. Environ. Prot., 2018, 114, 123-132.

35 X. Ke, S. A. Bernal, N. Ye, J. L. Provis and J. Yang, J. Am. Ceram. Soc., 2015, 98, 5-11.

36 J. He, J. Zhang, Y. Yu and G. Zhang, Constr. Build. Mater., 2012, 30, 80-91.

37 N. Ye, J. Yang, S. Liang, Y. Hu, J. Hu, B. Xiao and Q. Huang, Constr. Build. Mater., 2016, 111, 317-325.

38 R. Cetintas and S. Soyer-Uzun, J. Build. Eng., 2018, 20, 130136.

39 J. N. Y. Djobo, A. Elimbi, H. K. Tchakoute and S. Kumar, Physical and mechanical properties, RSC Adv., 2016, 6, 39106-39117.

40 J. He, Y. Jie, J. Zhang, Y. Yu and G. Zhang, Cem. Concr. Compos., 2013, 37, 108-118.

41 K. Okada, Y. Kameshima and A. Yasumori, J. Am. Ceram. Soc., 1998, 81, 1970-1972.

42 A. Ayame and T. Kitagawa, Bunseki Kagaku, 1991, 40, 673678.

43 H. Y. He, T. L. Barr and J. Klinowski, J. Phys. Chem., 1994, 98, 8124-8127.

44 C. Li, J. Wan, H. Sun and L. Li, J. Hazard. Mater., 2010, 179, 515-520.

45 M. R. North and T. W. Swaddle, Inorg. Chem., 2000, 39, 26612665.

46 A. Bauer, B. Velde and G. Berger, Appl. Geochem., 1998, 13, 619-629.

47 G.-H. Cai, S.-Y. Liu and X. Zheng, Constr. Build. Mater., 2019, 204, 84-93.

48 C. Chen, P. Zhang, G. Zeng, J. Deng, Y. Zhou and H. Lu, Chem. Eng. J., 2010, 158, 616-622.

49 Z. Abbas, A. P. Moghaddam and B. M. Steenari, Waste Manag., 2003, 23, 291-305.

50 W. Shin and Y.-K. Kim, J. Soils Sediments, 2016, 16, 726-735. 51 A. I. Badanoiu, T. H. A. Al Saadi, S. Stoleriu and G. Voicu, Constr. Build. Mater., 2015, 84, 284-293.

52 P. Duxson, A. Fernandez-Jimenez, J. L. Provis, G. C. Lukey, A. Palomo and J. S. J. van Deventer, J. Mater. Sci., 2007, 42, 2917-2933.

53 J. G. Jang, S. M. Park and H. K. Lee, J. Hazard. Mater., 2016, 318, 339-346. 